\title{
Molecular Detection of Bacillus anthracis in Beef Sample Recovered from an Anthrax-Endemic Village of India
}

\author{
N. Sahoo ${ }^{1 *}$, D. Hemadri ${ }^{2}$, S. Sahoo ${ }^{2}$, B. Behera ${ }^{1}$, A. Pahari ${ }^{1}$, \\ M. Dash ${ }^{1}$, S. Satpathy ${ }^{3}$ and M. Dolai ${ }^{3}$ \\ ${ }^{1}$ Centre for Wildlife Health, Odisha University of Agriculture and Technology, India \\ ${ }^{2}$ Indian Council of Agricultural Research-National \\ Institute of Veterinary Epidemiology and Disease information, India \\ ${ }^{3}$ Department of Animal Husbandry and Veterinary Services, Koraput, Odisha, India \\ *Corresponding author
}

\section{A B S T R A C T}

\begin{tabular}{|l|}
\hline Ke y w or d s \\
$\begin{array}{l}\text { Bacillus anthracis, } \\
\text { bullock, meat, real } \\
\text { time PCR }\end{array}$ \\
\hline Article Info \\
\hline $\begin{array}{l}\text { Accepted: } \\
\text { 18 May } 2020 \\
\text { Available Online: } \\
\text { 10 June } 2020\end{array}$ \\
\hline
\end{tabular}

Anthrax is a bacterial zoonoses caused by Bacillus anthracis that primarily affects herbivores, especially cattle. Human incidence is preceded by outbreaks in animals where infection is acquired through contact or ingestion of contaminated meat, or animal products. Present study deals with TaqMan real time PCR detection of B. anthracis in uncooked beef sample collected from an anthrax-endemic village in Boipariguda block of Koraput district, Odisha, India following reports of cutaneous anthrax in humans. Meat samples of a 7 years old bullock with signs of pyrexia and bloat was traced from the area where the carcass was de-skinned and disbursed. Molecular test revealed presence of capsule (Cap) and protective antigen (PA) of B. anthracis. Characteristic sigmoid curves were observed for both the genes. Cap gene-TaqMan PCR of the test sample had a Ct value of 23.53 whereas positive control had a value of 17.81 . Ct values were 17.22 and 24.03 for the positive control and the test sample, respectively. Positive results obtained for both the genes indicated the presence of a virulent strain in the area under study. Source of human anthrax with its mode of transmission demands strengthening of vaccination to livestock and awareness program in the area.

\section{Introduction}

Anthrax is a globally distributed bacterial zoonotic disease with the current human morbidity and/or mortality burden of 20,000 to 1,00,000 cases/year (1). Disease, though sporadic in North America and Northern Europe, is more common in Eastern and Southern Europe and hyper-endemic in Sub-
Saharan Africa, Middle East, Central and Southwest Asia including India. Anthrax, caused by Bacillus anthracis, is an endospore-forming, non-motile, gram-positive, capsulated, bacillus (rod shaped) with truncated ends. This bacterium has more than 1,200 strains and classified under two major clonal groups i.e., A and B, with several minor clusters in $\mathrm{A}$ branch and 
two minor clusters in the B branch. A and B2 branch isolates are distributed worldwide whereas B1 branch is found only in South Africa (2). Vegetative forms of bacilli sporulate on exposure to oxygen. Spores are extremely resistant to heat, desiccation, cold, chemicals and irradiation allowing them to survive in the environment, especially soil, for decades (3-4). Soil with high calcium, moisture, organic matter and $\mathrm{pH}>6.0$ favor spore survival (5). Natural anthrax outbreaks usually occur with onset of rain following prolonged hot and dry period.

Susceptibility to anthrax varies between mammalian species. Herbivores like cattle, sheep, goat, zebra, and elephant are most susceptible. Carnivores and omnivores are moderately resistant. Scavengers have the greatest resistance. Ostrich, a non-mammalian species, is also susceptible. However, amplifier host in the ecosystem is variable in different geolocations (6).

Unimmunized livestock, usually cattle, coming in contact with spore through contaminated water and grass from the environment become sick. Clinical signs of anthrax in cattle include depression, dyspnea, convulsions, tremors, ruminal stasis, anorexia, abortion, and drop in lactation. Edema may develop on neck, ventral chest and abdomen. Septicemia with high fever, tachypnea, congestion of mucous membranes followed by sudden death are terminal signs.

Death is unavoidable if anthrax affected cases are not treated aggressively. Carcass shows incomplete rigor mortis and rapid bloating with discharge of dark blood from natural orifices that fails to coagulate. Petechial or ecchymotic hemorrhage and blood-tinged serous fluid, enlarged pulpy spleen are major necropsy findings. Affected carcass, if improperly disposed off or handled, becomes source of infection for humans and contaminates the environment further. Human incidence primarily follows outbreaks in animals and infection is typically acquired through contact or ingestion of contaminated meat, or animal products.

Laboratory diagnosis is focused on processing of clinical samples such as blood and /or tissues for detection of bacilli/capsule, culture and isolation of $B$. anthracis or PCR detection of target genes for capsule and toxin. Disease control in livestock is through annual vaccination prepared with Sterne spore noncapsulating strain $34 \mathrm{~F}$ of $B$. anthracis.

Earlier reports highlighted incidence of cutaneous anthrax in Koraput, an anthrax-endemic district of India (7-8). Present report deals with real time PCR detection of B. anthracis in the uncooked beef sample recovered from a village of the same district following reports of cutaneous anthrax in humans.

\section{Materials and Methods}

On March 03, 2020, news of cutaneous anthrax in 04 adult males aged between 42-56 years was surfaced in a village Rupuguda (latitude: 18.782869 and longitude: 82.279646), Block: Boipariduda, District: Koraput, State: Odisha, India. A field investigation was conducted to trace out the possible source of infection. Careful interrogation of the local villagers revealed that a 7 years old bullock of indigenous breed had died in the village on February 12, 2020 with signs of pyrexia and bloat, the meat of which was consumed by the villagers.

In this study recovered small pieces of dry boneless meat ( $38 \mathrm{~g}$ ) from the area where the carcass was de-skinned and disbursed. Meat samples were collected and brought to the laboratory on frozen ice in plastic container adopting appropriate procedures of three 
layers package for $B$. anthracis testing. Keeping in view the possibility of soil contamination, the ground was burnt with locally collected dry plant materials to decontaminate the soil before proceeding to the laboratory. On March 07, 2020 samples were screened by TaqMan Real Time PCR.

\section{TaqMan real time PCR}

$25 \mathrm{mg}$ of the beef sample was placed in a $1.5 \mathrm{ml}$ microcentrifuge tube. $180 \mu \mathrm{l}$ of buffer ATL and $20 \mu 1$ of proteinase $\mathrm{K}$ was added to it followed by vortexing and incubation at $56^{\circ} \mathrm{C}$ for 3 hours. Purification of DNA from beef samples was done using Purelink Microbiome DNA Purification kit (Thermo Fisher Scientific) following the manufacturer's instructions.

The amplification reactions were carried out in a total volume of $25 \mu 1$ consisting of $5 \mu 1$ of template DNA and $20 \mu 1$ of master mixture. The latter consisted of $2 \mathrm{X}$ real time universal PCR MM (12.5 $\mu 1), 10 \mu \mathrm{M}$ forward and reverse primers $(0.75 \mu \mathrm{l})$ and $10 \mu \mathrm{M} 6 \mathrm{FAM}$ probe $(0.25 \mu \mathrm{l})$, made upto $20 \mu \mathrm{l}$ with molecular-grade water. The assay was performed in Rotor-Gene Q instrument with protocol comprising 1 cycle at $95^{\circ} \mathrm{C}$ for 10 min (hot start) followed by 50 cycles each at $95^{\circ} \mathrm{C}$ for $15 \mathrm{sec}$ (denaturation) and $60^{\circ} \mathrm{C}$ for $1 \mathrm{~min}$ (annealing). Data analysis was performed using Rotor-Gene Q software and $\mathrm{Ct}$ values were determined on the basis of mean baseline signals during the early cycles of amplification. The sequences of the $B$. anthracis-specific primers and probes are given in table 1 (9). $200 \mu \mathrm{l}$ of blood sample collected in EDTA vial from an apparently healthy adult cow was used as negative control.

The plasmid $\mathrm{pLepBaBp}+$ was used as positive control. This plasmid produces short peptide sequences for several bacterial species including Bacillus anthracis, Leptospira spp. and Burkholderia pseudomallei. The plasmid also contains a sequence for RNase P which serves as an internal control for human DNA (9).

\section{Results and Discussion}

Anthrax is an OIE listed disease of public health importance. Spores of the causative agent, B. anthracis, were utilized as a bioterrorism agent. Hence, about 150 years after the development of vaccine by Louis Pasteur, anthrax is still addressed on top priority. Humans get infection from livestock. Generally, anthrax is not transmissible from person-to-person. Four forms of human anthrax are recognized viz., cutaneous, gastrointestinal, pulmonary and injection anthrax (10). Cutaneous anthrax that generally results from contact with contaminated animal product is common and accounts for about $95 \%$ cases. Koraput, a tribal dominated district of Odisha, is endemic for anthrax (7). In a study covering 10 cases of cutaneous anthrax from Koraput district, the above authors have made the diagnosis based on the history of slaughtering of sick animal or contact with animal product, clinical signs of cutaneous ulcer with black eschar, edema or papules or vesicles and microbiological examination (staining) of the exudates taken from the floor of ulcer.

Advantages of PCR, as adopted in the present study, is less time consuming, sensitive and involves low risk of bacterial propagation. The Cap and PA gene-TaqMan PCR from of the beef sample revealed characteristic sigmoid curves. Cap gene-TaqMan PCR of the test sample showed a $\mathrm{Ct}$ value of 23.53 as against the positive control, which had a value of 17.81. Ct values of 17.22 and 24.03 for the positive control and the test sample, respectively, were obtained in the PA geneTaqman PCR. 
Absence of amplification in negative control and RP gene of sample was an indicator of validity of test results. We could not carry out multiple locus variable-number tandemrepeat analysis (MLVA) in our study; however, this can be useful for source tracking of the pathogenic isolates (11).

B. anthracis has two virulence factors, toxin producing genes on plasmid pX01 and capsule formation genes on $\mathrm{pX} 02$. Loss of either of these factors decreases the virulence significantly. Therefore, primers to one of the toxin genes (usually protective antigen) as well as one of the capsule genes are used to confirm the presence of virulent $B$. anthracis (12). The positive results obtained for both of the above genes in our study indicated that the strain involved was indeed a virulent one.

Usefulness of TaqMan and nested PCR in the diagnosis of anthrax has been reported by few researchers. Four cutaneous anthrax cases in China were caused by butchering of a sick cow through real time PCR targeting rpoB, pagA, and cap genes of $B$. anthracis (11).

These workers have reported that eschar samples from all four human cases as well as the meat sample were positive for all three $B$. anthracis genes. Presence of $B$. anthracis chromosomal DNA and the pX01/pX02 plasmids in meat samples were confirmed using nested PCR. They concluded that such method could detect one cell of $B$. anthracis from $1 \mathrm{~g}$ of the biosample (13).

As per the livestock census 2019, Koraput district has the domestic herbivore population of $7,81,305$ that includes $4,46,338$ cattle, 61 , 293 buffaloes, 1, 29,187 sheep and 1, 44, 487 goats. Susceptible animals are generally vaccinated annually with the state Government manufactured anthrax spore vaccine.
However, molecular diagnosis of B. anthracis from the recovered sample has confirmed death of bullock due to anthrax in the village. Such a situation raised two issues; first, there could be lapses in the vaccination and second, direct contact of villagers with anthrax-infected livestock/meat. Present findings give us a lesson to implement a stringent vaccination program and ensure complete coverage. It is important to note that cattle in the area are predominantly reared for ploughing and collection of dung. These animals are let loose for free ranging during most part of the year and when the need arises, they are herded in a community shelter during the night.

Obviously, there is no shelter at individual owner level. Considering the existing animal husbandry practice in the Koraput district and results of our study, the district veterinary department has proposed to introduce tagging of each vaccinated animal that would ensure identity of the vaccinated stock. Additionally, a point of care diagnostics would be helpful for onsite diagnosis of anthrax in an exceptional situation.

The Centers for Disease Control and Prevention (CDC), USA has developed a framework that outlines a start-to-finish approach to improve the prevention of anthrax outbreaks (14). The framework which is divided into two phases: (1) assessment of the existing situation and systems and, (2) evaluation of strengths, weaknesses, and barriers. The principles and methods described in this framework with respect to implementation of prevention and control measures could be applied to the area under study. Regular vaccination of all susceptible domestic animals, intersectoral cooperation, ensuring proper pre-slaughter inspection, and educating animal handlers about this disease are planned to prevent $B$. anthracis infection in the future. 
Table.1 Primers and probes used in the TaqMan PCR assay

\begin{tabular}{|c|c|}
\hline Targets & Sequence (5'-3') \\
\hline \multirow[t]{3}{*}{ Capsule (Cap) } & CAP F ACGTATGGTGTTTCAAGATTCATG \\
\hline & CAP R ATTTTCGTCTCATTCTACCTCACC \\
\hline & (6FAM) CCACGGAATTCAAAAATCTCAAATGGCAT (BHQ1) \\
\hline \multirow{3}{*}{$\begin{array}{c}\text { Protective } \\
\text { antigen (PA) }\end{array}$} & PA F CGGATCAAGTATATGGGAATATAGCAA \\
\hline & PA R CCGGTTTAGTCGTTTCTAATGGAT \\
\hline & (6FAM) CTCGAACTGGAGTGAAGTGTTACCGCAAAT (BHQ1) \\
\hline \multirow[t]{3}{*}{ RNase P (RP) } & RP F AGATTTGGACCTGCGAGCG \\
\hline & RP R GAGCGGCTGTCTCCACAAGT \\
\hline & (6FAM) TTCTGACCTGAAGGCTCTGCGCG (BHQ1) \\
\hline
\end{tabular}

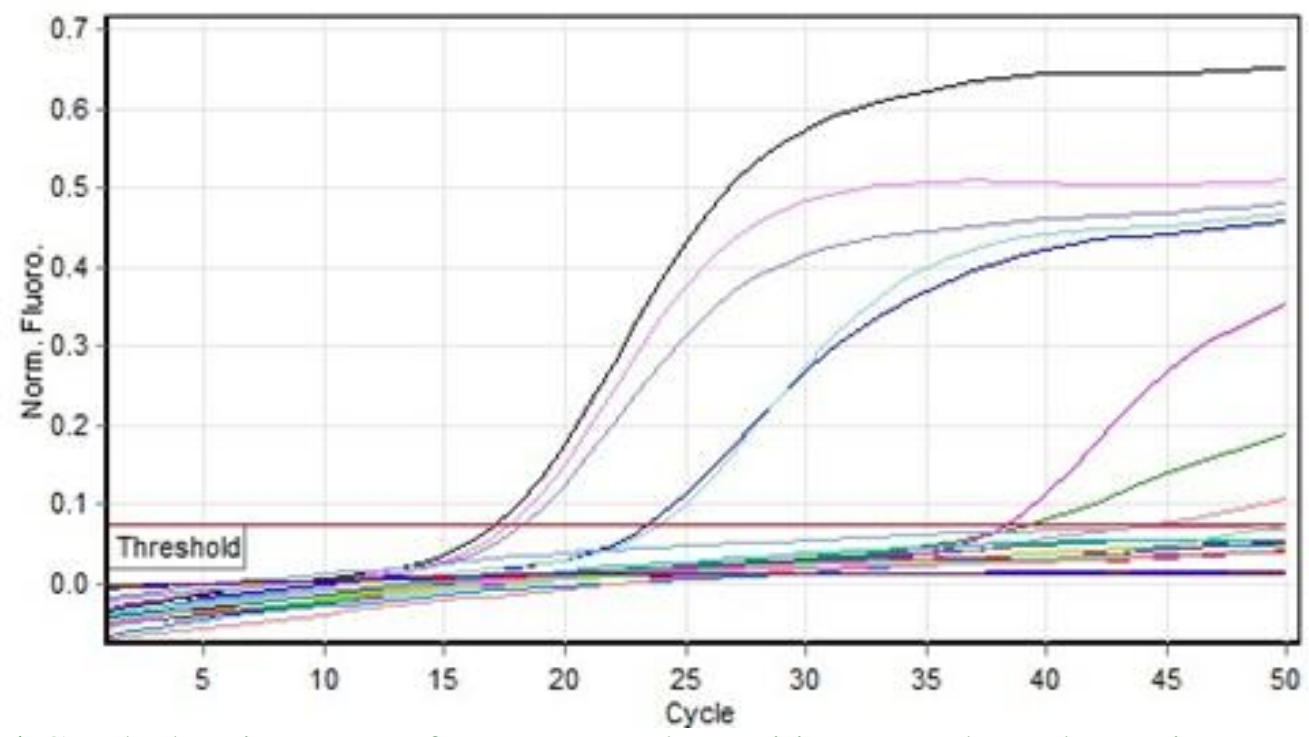

Fig.1 Graph showing curves for meat sample, positive controls, and negative controls

In this study, B. anthracis was detected through Taqman PCR in the beef samples recovered 24 days after slaughter of one bullock from an anthrax-endemic village of Koraput district, India with the concurrent incidence of cutaneous anthrax in in-contact humans. Study confirmed incidence of cattle anthrax as well as source and mode of transmission to humans and thereby triggered strengthening of livestock vaccination and awareness program among the villagers.

\section{Acknowledgment}

Authors are thankful to Dr. J. S. Salzer and Dr. D. J. S. N. Birdsell, Centers for Disease Control and Prevention, USA and Dr. M. Papanna and Dr. R. Jessica, University of Pennsylvania, USA for their technical support and guidance. 


\section{References}

1. Kamal SM, Rashid AK, Bakar MA, Ahad MA (2011) Anthrax: an update. Asian Pac J Trop Biomed. 1(6):496-501. 10.1016/S22211691(11)60109-3.

2. Keim P, Smith KL (2002) Bacillus anthracis evolution and epidemiology. Current Topics in Microbiology and Immunology 271: 23-32. 10.1007/978-3-662-05767-4 2

3. Mock M, Fouet A (2001) 'Anthrax'. Annual reviews in Microbiology 55:647-661. https://doi.org/10.1146/annurev.micro. 55.1.647

4. Shivachandra SB, Chanda MM, Reddy GMB, Hemadri D (2016) Anthrax at a glance. Indian Council of Agricultural Research-National Institute of Veterinary Epidemiology and Disease informatics (NIVEDI), Bengaluru, India.

5. Himsworth CG (2008) The danger of lime use in agricultural anthrax disinfection procedures: The potential role of calcium in the preservation of anthrax spores. Can Vet J 49(12): 1208-1210.

6. Miller RE, Fowler ME (2011) Zoo and Wild Animal Medicine Current Therapy, Elsevier

7. Das BB, Dash NC, Mishra J (2017) Association of Bacillus anthracis in cutaneous ulcers in Koraput, Odisha, Paripex. Indian Journal of Research 6:95-100.
8. Nayak P, Sodha SV, Laserson KF et al., (2019) A cutaneous Anthrax outbreak in Koraput District of Odisha-India 2015. BMC Public Health 19: 470. 10.1186/s12889-0196787-0

9. Anonymous. 2020. Manual on 'Bacillus anthracis sample collection, gram stain and polymerase chain reaction' prepared by the Centers for Disease Control and Prevention, USA.

10. Sweeney DA, Hicks CW, Cui X et al., (2011) Anthrax infection. Am J Respir Crit Care Med 184(12):1333-41. 10.1164/rccm.201102-0209CI

11. Tan Z, Qi X, Gu L et al., (2014) Molecular characterization of Bacillus anthracis directly from patients' eschar and beef in an anthrax outbreak in Jiangsu Province, China, 2012. Am $J$ Trop Med Hyg 91(3):574-576. https://doi.org/10.4269/ajtmh.13-0633

12. Turnbull $P$ (2008) Anthrax in humans and animals. Geneva, Switzerland, WHO Press

13. Cheun HI, Makino SI, Watarai M et al., (2001) A Simple and sensitive detection system of Bacillus anthracis in meat and tissue. Journal of applied microbiology 91(3): 421-6. 10.1046/j.1365-2672.2001.01395.x

14. Vieira AR, Salzer JS, Traxler RM et al., (2017) Enhancing Surveillance and Diagnostics in Anthrax-Endemic Countries. Emerg Infect Dis 23(13):147-53. 10.3201/eid2313. 170431.

\section{How to cite this article:}

Sahoo. N., D. Hemadri, S. Sahoo, B. Behera, A. Pahari, M. Dash, S. Satpathy and Dolai. M. 2020. Molecular Detection of Bacillus anthracis in Beef Sample Recovered from an Anthrax-Endemic Village of India. Int.J.Curr.Microbiol.App.Sci. 9(06): 2228-2233. doi: https://doi.org/10.20546/ijcmas.2020.906.272 